\title{
Ensuring an Essential Supply of Allied Health Professions (AHP) Placements: Using Crowdsourcing to Develop a National Call to Action
}

\author{
*Janice St. John-Matthews ${ }^{a}$, Char Hobbs ${ }^{b}$, Paul Chapman ${ }^{c}$, David Marsden ${ }^{c}$, Ruth \\ Allarton ${ }^{c}$, Austin Booth ${ }^{d}$, Fiona Martin ${ }^{e}, J_{\text {Jie Woodley }}^{a}, \&$ Beverly Harden ${ }^{b c}$ \\ a: The University of the West of England, United Kingdom; $b$ : The University of Winchester, \\ United Kingdom; c: Health Education England, United Kingdom; d: Subject advisor to Health \\ Education England, United Kingdom; e: Clever Together Lab Ltd., United Kingdom
}

\begin{abstract}
Sustainable growth in the Allied Health Professions (AHP) workforce is an ambition of the United Kingdom's NHS Long Term Plan. However historically, access to good quality placements has been a barrier to increasing pre-registration training numbers. This article focuses on work carried out by Health Education England (HEE) to gain insights on the impact of the COVID-19 pandemic on capacity. Using a pragmatic, embedded mixedmethods approach, insights were gathered using an online workshop, crowdsourcing, open for two weeks in the summer of 2020. AHP placement stakeholders could vote, share ideas or comment. Descriptive data were extracted, and comments made were analysed using inductive thematic analysis. Participants $(N=1,800)$ made over 8,500 comments. The themes identified included: diversity of placement opportunity, improved placement coordination, a more joined-up system, supervision models and educator capacity. Alongside considering the challenges to placement capacity, several areas of innovative practice owing to the pandemic were highlighted. Generated insights have shaped the aims and objectives of the Health Education (HEE) pre-registration AHP student practice learning programme for 2020/2021 and beyond. The COVID-19 pandemic has disrupted the delivery of AHP placements. In the absence of face-to-face activities, crowdsourcing provided an online data collection tool offering stakeholders an opportunity to engage with the placement capacity agenda and share learning. Findings have shaped the HEE approach to short-term placement recovery and long-term growth.
\end{abstract}

Keywords: allied health professions; crowdsourcing; pandemic; placements

*Corresponding Author: Janice St. John-Matthews, Research in Health Professions Education (RiPHE), Swansea University, Medical School, Swansea, SA2 8PP, United Kingdom.

Email: 847270@swansea.ac.uk

Journal URL: https://publications.coventry.ac.uk/index.php/pblh

St. John-Matthews, J., Hobbs, C., Chapman, P., Marsden, D., Allarton' R., Booth, A., Martin, F., Woodley, J., \& Harden, B. (2021). Ensuring an essential supply of Allied Health Professions (AHP) placements: using crowdsourcing to develop a national call to action. International Journal of Practice-based Learning in Health and Social Care, Care, 9(2), 49-62, DOI 10.18552/ijpblhsc.v9i2.732

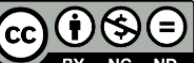

CC ${ }_{\text {BY NC ND }} 2021$ Janice St. John-Matthews, Char Hobbs, Paul Chapman, David Marsden, Ruth Allarton, Austin Booth, Fiona Martin, Julie Woodley, \& Beverly Harden. This Open Access article is distributed under the terms of the Creative Commons Attribution Attribution-Non-Commercial No Derivatives 4.0 International License (https://creativecommons.org/licenses/by-nc-nd/4.0/ ), which permits unrestricted non-commercial use, distribution, and reproduction in any medium, provided the original work is properly cited and is unaltered. 


\section{Introduction}

Allied Health Professions (AHPs) form the third-largest clinical workforce in health and social care in England, providing system-wide care to assess, treat, diagnose, and discharge patients across social care, housing, education, independent and voluntary sectors. AHPs comprise of 14 distinct occupations, including art therapists, dietitians, drama therapists, music therapists, occupational therapists, operating department practitioners, orthoptists, osteopaths, paramedics, physiotherapists, podiatrists, prosthetists, and orthotists, diagnostic and therapeutic radiographers, and speech and language therapists. Thirteen of the 14 AHPs are regulated by the Health and Care Professions Council (HCPC), with osteopaths regulated by the General Osteopathic Council (GOsC) (NHS England [NHSE], 2020). By adopting a holistic approach to healthcare, AHPs can help manage patients' care from birth to end of life care. They focus on prevention, improving health and well-being to maximise people's potential to live full and active lives within their family circles, social networks, education/training, and the workplace (NHS Improvement [NHSI], 2018).

The We Are the NHS: People Plan 2020/2021 (NHS England [NHSE], 2020) states that post COVID-19, employers should fully integrate education and training into their plans to rebuild and restart clinical services, releasing the time of educators to continue the growth of the workforce, including supporting the expansion of clinical placement capacity. Health Education England (HEE) is supporting the national AHP workforce programme by setting out the action needed to improve the supply and retention of AHPs. This workstream will ensure that by 2024, the right AHP workforce with the right skills is in the right place to deliver high-quality care (Health Education England [HEE], 2017). HEE is working collaboratively across universities, professional bodies, the Office for Students (OfS), and regulators to share learning and build ambition to deliver on the supply agenda. As most AHPs qualify through preregistration education, ensuring growth in this route is central to achieving this aim. Alongside this, work is also being carried out in growing the apprenticeship offer, Reducing Pre-registration Attrition and Improving Retention (RePAIR project), international recruitment of AHPs and the Return to Practice programme (RtP) that aims to help AHPs re-join the register (HEE, 2020).

Given that AHP training programmes have clinical and academic components, a robust and sustainable approach to sound quality placements and learning environments is critical to effectively expanding the workforce by growing AHPs in education. These learning environments are not just physical spaces; they include all that surrounds a learner, including equipment, staff, fellow learners, and supervisors (Fenton, 2005). Whilst the structure and the time spent in each of these areas varies by profession, the primary purpose of a placement is to develop practitioners who are fit to practice, thus allowing eligibility to register with their respective regulator. As a result, the function of these learning environments is not only to develop practical skills but also to underpin theoretical knowledge learnt within the classroom. The clinical setting is often the classroom for students during placements, so this learning environment should benefit the student. However, there are links between poor placement experiences and attrition rates.

Good quality placement capacity is often cited as a challenge in specific courses or geographies. Recently, this tension has been accelerated by the global COVID-19 pandemic. By May 2020, more than 3.5 million people worldwide had contracted COVID-19, with over 250,000 dying (World Health Organisation [WHO], 2020). Although pandemics are classed as low frequency and low controllable events (Akkermans et al., 2020), it has been a highly disruptive and extraordinary event with a farreaching impact on placement logistics and provision. Propelled by the pandemic and the announcement in May 2020 by the Education Secretary of an additional 5,000 ring-fenced university places in England for the 2020/2021 academic year for nursing, midwifery, and allied health courses (Department of Health and Social Care [DHSC], 2020), the HEE AHP Clinical Placement Expansion Programme (CPEP) took the form of three key areas:

(1) An AHP student placement online and virtual workshops (crowdsource)

(2) A student clinical placement webinar series

(3) A call for bids for HEE Clinical Placement Expansion Programme (CPEP) funds

\section{Problem statement}

There is a shortage of good quality AHP placements within England as there has been no drive to build placement capacity. This shortage is against the need to increase the numbers of AHPs in the workforce, 
to meet the needs of the NHS Long Term Plan, and a global pandemic that has made accessing traditional clinical placements, settings and types, challenging. In the midst of harnessing increased capacity, COVID-19 meant tens of thousands of lost placement hours for pre-registration learners, including AHPs across England. Thus the double challenge of lost placement hours in a system already short of placement hours emerged. Nevertheless, placements are critical to the training of the future pre-registration workforce. To explore the challenges and capture the insights and adaption to placement approaches during COVID-19 for Higher Education Institutes (HEIs) that placement providers and learners had adapted throughout COVID-19, this article focuses on the outputs from a national AHP student placement online workshop, crowdsourcing, carried out in summer 2020. By introducing the reader to crowdsourcing, the article outlines how insights from this approach have influenced the ongoing 2020/2021 HEE CPEP work to meet the Long Term Plan 2024 objective of having the right AHP workforce with the right skills in the right place to deliver high-quality care.

\section{Method}

Solutions to the problems that clinical placement scarcity presents were central to this pragmatic embedded mixed-methods research approach rather than a philosophical discussion about the reality of placements. Therefore, all methods that would contribute to an understanding of current placement capacity challenges and potential solutions were embraced, with the inquiry seeking to find 'what works' within and across professions and sharing this with the wider AHP community. Consequently, the research problem, rather than the philosophical and ideological assumptions, guided the study (Efron \& Ravid, 2020).

\section{The data collection tool}

The online workshop took the form of a crowdsource provided by the company Clever Together Lab Ltd. (Clever Together, 2020). Crowdsourcing is a policy development and business technological enabler that works through an institution, outsourcing a function usually performed by an employee or group of individuals (Howe, 2006) whereby crowdsource users, known as the crowd, form a spontaneous community who undertake a task which typically involves the pooling of knowledge resources. Crowdsourcing has three core elements: an organisation having a task it needs to be performed, a community voluntarily willing to complete the task, and the potential to create results that are of mutual benefit for the organisation and the community (Brabham, 2013). Unlike the Delphi technique, which relies only on the opinions of a small number of specialists, crowdsourcing can harness the views of a broader range of people to address "messy problems which require a diversity of opinion" (Flostrand, 2017, p. 234). Moreover, this form of self-selecting engagement through an open call, whilst not necessarily representative of populations, seeks equality of opportunity to engage. Therefore, it can help support management decision-making by exposing the real-life experience of participants and their collective insight; and identifying or evaluating potential solutions. In short, it can deliver insight into complex issues. This contrasts crowdfunding (raising monies via a crowd) and crowdlearning, and subsequently, crowdsourcing should not be confused with these other types of crowd activities.

Nevertheless, like any data collection tool, crowdsourcing is not without its challenges. For example, facilitating the exchange of ideas, compared to a survey in which opinions are expressed in individual isolation, creates the potential for 'crowd think', where minority opinions are ignored. Despite this challenge, carefully executed crowdsourcing campaigns can be valuable exercises that allow organisations to engage with stakeholders to elicit new ideas (Taeihagh, 2017). Subsequently, the Clever Together platform design and techniques used to analyse the feedback are intended to mitigate the bias risks.

In a narrative literature review of crowdsourcing in healthcare education undertaken by St. JohnMatthews et al. (2019), 17 empirical studies were returned. The literature identified was assessed against an established crowdsourcing definition, the 8-point Estellés-Arolas and González-Ladrón-de-Guevara (2012) crowdsourcing verification tool (Figure 1). Reviewing these yielded four themes for discussion: student selection procedures, lesson planning, teaching materials, and assessment. The review concluded that crowdsourcing is associated with innovative activities through collective solution-seeking via an extensive network of users and is increasingly adopted in healthcare education research. 
Figure 1.

An 8-point crowdsourcing verification tool (Estellés-Arolas \& González-Ladrón-de-Guevara, 2012, p. 191)

About the crowd

(1) Who forms the crowd?

(2) What the crowd must do

(3) What the crowd gets in return

About the initiator

(4) Who is the crowdsourcer?

(5) What the crowdsourcer gets in return for the work of the crowd

About the crowdsourcing process

(6) What type of process is it?

(7) What type of call is it?

(8) What medium or platform is used

If crowdsourcing is not carefully planned, it can result in large amounts of data that do not help solve the problem (Brabham, 2013) and may lead to the project's failure. To mitigate this risk and support reader navigation of the methods used in this research, the aforementioned Estellés-Arolas and GonzálezLadrón-de-Guevara (2012) eight-point crowdsource verification tool was adopted. Using this verification tool provided a quality check opportunity to be applied to the crowdsourcing activity. This framework was developed following the systematic review of six scientific databases. From the 209 documents reviewed, 40 unique definitions of crowdsourcing were identified and used to create a final 8-point verification instrument. This tool describes three elements: the crowd, the initiator, and the process from which eight characteristics are extracted. Estellés-Arolas and González-Ladrón-de-Guevara subsequently revisited their proposed verification instrument by conducting a similar literature review again, reviewing a further 28 articles (Estellés-Arolas et al., 2015). None of these articles identified a new element or characteristic.

\section{About the crowd (participants)}

For this crowdsourced activity, the crowd was the Allied Health Professions community. The workshop aimed to generate insight into how clinical placements could be expanded for AHPs. To explore this, the workshop asked participants to consider several critical questions concerning AHP placements and how to overcome the challenges presented by COVID-19. The workshop was open to anyone with an interest, including but not limited to, those in clinical placement provision, AHPs, representative bodies, or those looking to or having returned to practice. Although HEE commissioned the project, a co-creation approach including England, Northern Ireland, Scotland, and Wales was critical. The crowdsource was also opened to anyone from across the world.

Aitamaurto (2012) reminds us that crowdsourcing is not an automated process that always takes off quickly when launched on the web. On the contrary, awareness of the opportunity to participate must be spread and continually communicated throughout the process. For this workshop, ensuring we captured the voice of all AHPs, including those in training, was deemed a challenge. Due mainly to HEE's existing networks and links with the professional bodies, including the Health and Care Professions Council (HCPC), the conversation proved to be popular. HEE worked with the individual AHP professional bodies and the Council of Deans of Health $(\mathrm{CoDH})$ to promote the discussion to their members to generate a breadth of interest. HEE also worked with colleagues in Health Education and Improvement Wales (HEIW), NHS Education Scotland (NES) and Health and Social Care Northern Ireland (HSCNI) to ensure the four-nation voice was captured. There was also a high interest in Social Media in general (specifically via Twitter), with those promoting and discussing the topic using the \#AHPplacements and \#AHPplacement hashtags. 


\section{About the initiator}

Health Education England commissioned Clever Together in June 2020 to run the online workshop and generate insight on the impact of COVID-19 on placement capacity and how AHP placement provision could be expanded and improved.

\section{About the crowdsourcing process}

From the 23rd of June to the 7th of July 2020, the online workshop was hosted to crowdsource views from as many people as possible with an interest in AHP clinical placement capacity (HEE, 2020). A bespoke online platform was created with a unique URL,

https://ahpplacements.clevertogether.com/clinical-placements-expansion-programme. This platform offered online engagement, open 24 hours a day, seven days a week, where participants could join the conversations as many times as they wished. Whilst contributions to the platform were visible to other contributors, personal details were anonymised, thus ensuring others considered ideas on their merit rather than on who had posted them. On completing a gateway questionnaire, a survey about the individuals accessing the crowdsource, participants were invited to contribute to the debate by engaging with four challenge questions (Table 1). A fifth question asked participants to submit local projects on increasing placement capacity.

Table 1.

Online workshop challenge themes and challenge questions

\begin{tabular}{|lll|}
\hline \multicolumn{2}{|c|}{ Challenge theme } & Challenge question \\
\hline 1 Placement capacity across the system & $\begin{array}{l}\text { What do we need to stop doing, start doing or do differently if } \\
\text { we are to increase capacity for pre-registration clinical } \\
\text { placements for AHPs now and in the future? }\end{array}$ \\
3 Wuality of Placements & $\begin{array}{l}\text { How can we sustain and improve the quality of clinical } \\
\text { placements for pre-registration learners? }\end{array}$ \\
& $\begin{array}{l}\text { What do we need to improve so that we are working better } \\
\text { between education providers, placement providers and } \\
\text { commissioners or funders of clinical placements? }\end{array}$ \\
& $\begin{array}{l}\text { If you had a magic wand, what one thing would you change to } \\
\text { the way in which we plan, clinically educate, and train our } \\
\text { AHPs? }\end{array}$ \\
& $\begin{array}{l}\text { We know lots of innovative work is taking place to improve } \\
\text { how clinical placements are designed and delivered. Some of } \\
\text { these relate to COVID-19, but some are not. Whether it has } \\
\text { innovation }\end{array}$ \\
& $\begin{array}{l}\text { been formally recognised in published journals or captured } \\
\text { through your organisation's knowledge hubs or posters, we } \\
\text { want to hear about both. }\end{array}$ \\
\end{tabular}

\section{e-Consent}

Participants were asked to read the crowdsource ground rules before signing up (consenting) and entering the crowdsourcing platform. These rules highlighted that personal, abusive, or offensive content would not be tolerated. If this happened, participants could be contacted anonymously via email using a function available on the platform. The platform was moderated daily by the crowdsource team. As the crowdsource was conducted online, e-consent was in place, and participants had a tick box to confirm they were happy to contribute to the research and be contacted with the findings. E-consent is recognised by the NHS Health Research Authority (HRA) and the Medicines and Healthcare products Regulatory Agents (MHRA) as a credible alternative to conventional face-to-face consenting processes. In their review of e-consenting, Skelton et al. (2020) wrote that the articles they reviewed indicate user experiences of the process as positive, with moderate to high levels of satisfaction. They noted that 
several articles in their review also emphasised that e-consenting may improve participant diversity and inclusion by enabling underrepresented groups or participants in rural areas who would not usually join studies remotely.

\section{Data collected and analysed}

Although participation in the workshop was anonymous, several 'gateway' questions were asked of those registering to ascertain their role in clinical placement activity. The purpose of this was to enable us to analyse responses, broaden our understanding of the contributions made and conduct some data analytics to draw insight into the ideas, who generated them and assist the development of conclusions. For example, we wanted to check whether contributions were being made from a wide variety of professions (Figure 2).

Figure 2.

\section{Gateway questions}

(1) Are you an Allied Healthcare Professional (AHP)?

(2) If you are an AHP, please indicate which of the following best describes you?

(3) What is your primary role?

(4) What type of organisation is your primary employer?

(5) In which country do you work?

As with most online and crowdsourced workshops, participation could take several different forms:

- Participants could register, fill in the gateway questionnaire and observe the conversation

- Participants could propose ideas or make comments on ideas

- Participants could use the vote buttons to indicate support or not of any contribution

Pragmatically, the sample size was the number of people who engaged with the crowdsource during the two weeks, as the literature on sample sizes in crowdsourced activity is limited. This approach was in keeping with Braun and Clarke's (2019) observation that whilst the obsession with qualitative sample sizes may exist in some quarters, it relies on a mix of interpretative, situational, and pragmatic judgements. When the online workshop closed, all the data from the platform was downloaded. Descriptive categorical data was collected and reported. This included the demographic details of participants when participants accessed the webpage, where geographically they accessed the webpage from, how many ideas, comments and votes were cast. Using the voting tool enabled the reporting of the most discussed and the highest-rated ideas. However, voting only formed part of the reported results. As Wynne et al. (2007) highlighted, we needed to be cautious not to coalesce participant's concerns as this may lead to them being objectified and underestimated. Wynne et al. (2007) continue by observing that, unlike in big data analysis, where minority opinions or behaviour can be lost, crowdsourcing enables qualitative research that brings to light non-mainstream and dissonant voices. Hence while the votes were recorded, they were considered within the context of the qualitative data.

Whilst the overall epistemological approach for this research was pragmatic, this stance was revisited to analyse the comments and ideas generated within the crowdsource. Braun and Clarke (2006) observed that the need to revisit an epistemology stance during analysis occasionally happens, specifically when the research focus shifts to an interest in different aspects of the data. For this research, every contribution was read and coded by a team at Clever Together and three coders on behalf of HEE using inductive thematic analysis. This approach meant the themes identified were linked to the data themselves rather than fitting themes into the pre-existing coding frame (Braun \& Clarke, 2006). A constructivist approach 
was used for this set of data as this approach seeks to theorise the sociocultural contexts and structural conditions that enable the individual accounts that are provided. The coding was reviewed by another member of the Clever Together (2020) team for quality assurance. It is important to acknowledge that there will always be differences in views about what code to apply, but taking this approach ensured greater consistency and enabled us to be confident in the conclusions we drew from the conversation. The Clever Together and HEE coding teams coded separately and then had a consensus meeting to finalise the agreed themes.

\section{Results and crowd discussions}

The voting and commenting system that lead to a final decision in the crowdsourcing community was called 'the wisdom of the crowd'. This theory is based on the notion that participants working together are better at problem-solving than individuals (Brabham, 2008). Qualitative data collection tools such as interviews and focus groups are often focused on individual experiences, and views of those experiences are in focus. However, we were interested in the collective output with this crowdsourced activity, not the individual outcomes with our research (Eklund et al., 2019). The key to crowdsourcing is to have a diverse group- in this case, geographically and also across the 14 AHP professions (Lorenz et al. 2011) hence why this data is shared. With this lens, the demographic information was collected to demonstrate the crowd's diversity and the findings are reported as a synthesised narrative of the crowd discussions.

\section{Descriptive data: Online workshop}

Over 1,800 people engaged from different professions collectively making over 8,500 comments. Eightyfive participants did not give their consent for their data to be processed, therefore these data have not been included in the analysis. Contributions differed throughout the crowdsource sections, as seen in Table 2. Large numbers of ideas, comments, and votes stemmed from discussions around placement capacity and ideas for improvements.

Table 2.

Summary of the numbers of ideas, comments and votes presented for each section of the online crowdsource

\begin{tabular}{|c|c|c|c|}
\hline Title of Section & Ideas & Comments & Votes \\
\hline Placement capacity across the system & 147 & 678 & 4,545 \\
\hline Quality of placements & 48 & 83 & 760 \\
\hline Working effectively across the systems & 42 & 40 & 304 \\
\hline Your ideas for improvement & 97 & 220 & 1,125 \\
\hline Sharing examples of great practice and innovation & 41 & 42 & 320 \\
\hline
\end{tabular}

Figure 3 presents the percentage of each professional group or role that participated in the online crowdsource. Registered AHPs dominate this percentage with $87.3 \%$ of contributions from the crowdsource. Pre-registration AHP students followed this at a smaller 4.3\% $(n=52)$. 
Figure 3.

The primary role of participants

\section{Allied Health Profession \\ support worker \\ $0.4 \%$}

Returning to practice to be re-registered as an

Allied Health

Professional

$1.4 \%$

Not a registered

healthcare

professional

$2.4 \%$

Nurse/midwife

$2.4 \%$

Other

$1.8 \%$
Pre-registration Allied Health Professional student

$4.3 \%$

Registered Allied Health Professional $87.3 \%$

Figure 4.

Types of organisations

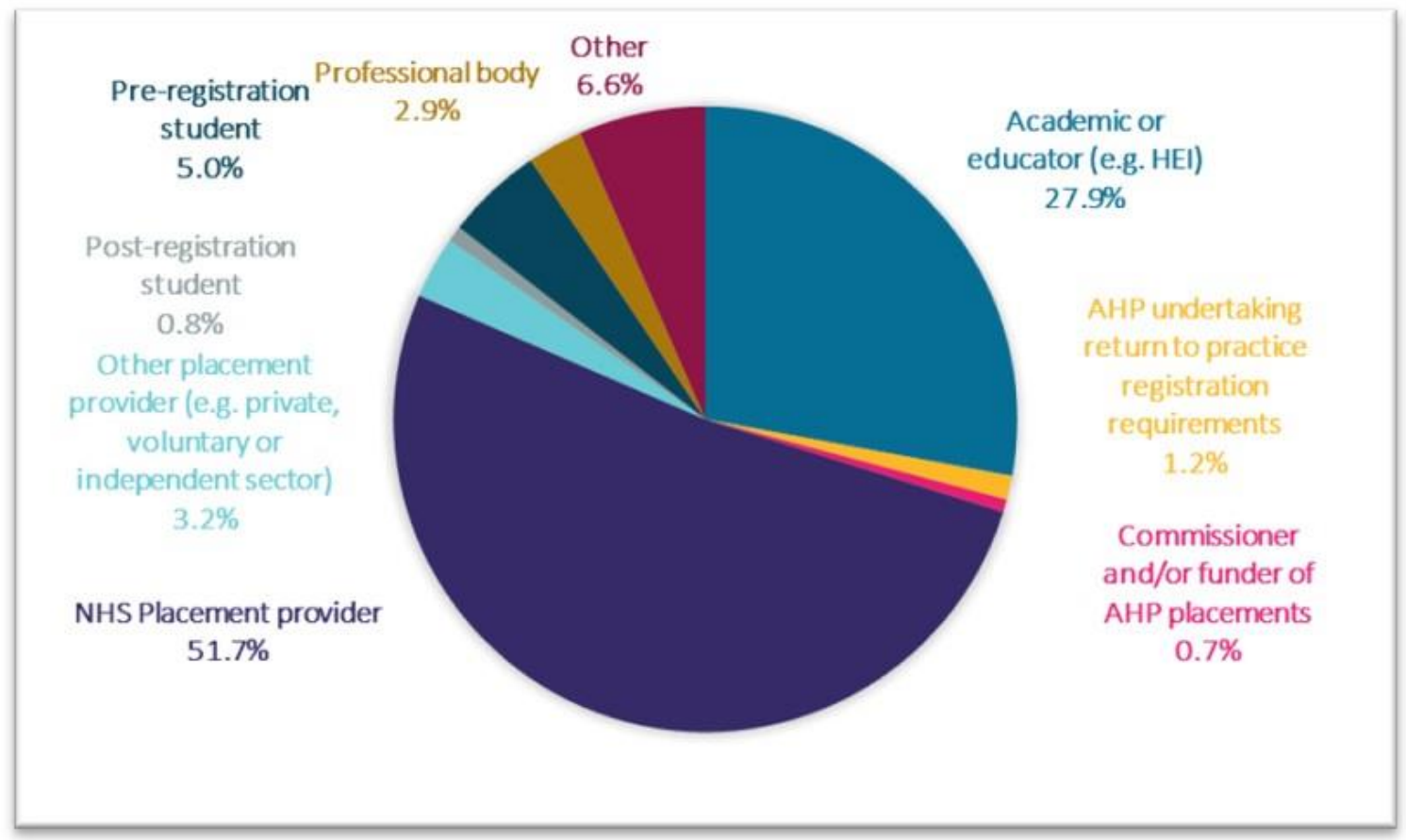

Over half the contributors were from an NHS placement provider (51.7\%), followed by over a quarter of academics or educators (27.9\%). The workshop also drew representation from professional bodies and commissioning groups (Figure 4). Contributions to the online crowdsource allowed us to recognise that every AHP profession joined the discussion (Figure 5). Noticeably, physiotherapy, occupational therapy 
and radiography professions participated the most, reflecting their size as a profession. Paramedics and ODPs made the lowest level of contributions. Small professions, like arts therapists, were able to participate as well.

Figure 5.

Percentage of participants by AHP, compared to the percentage of AHPs on the HCPC register

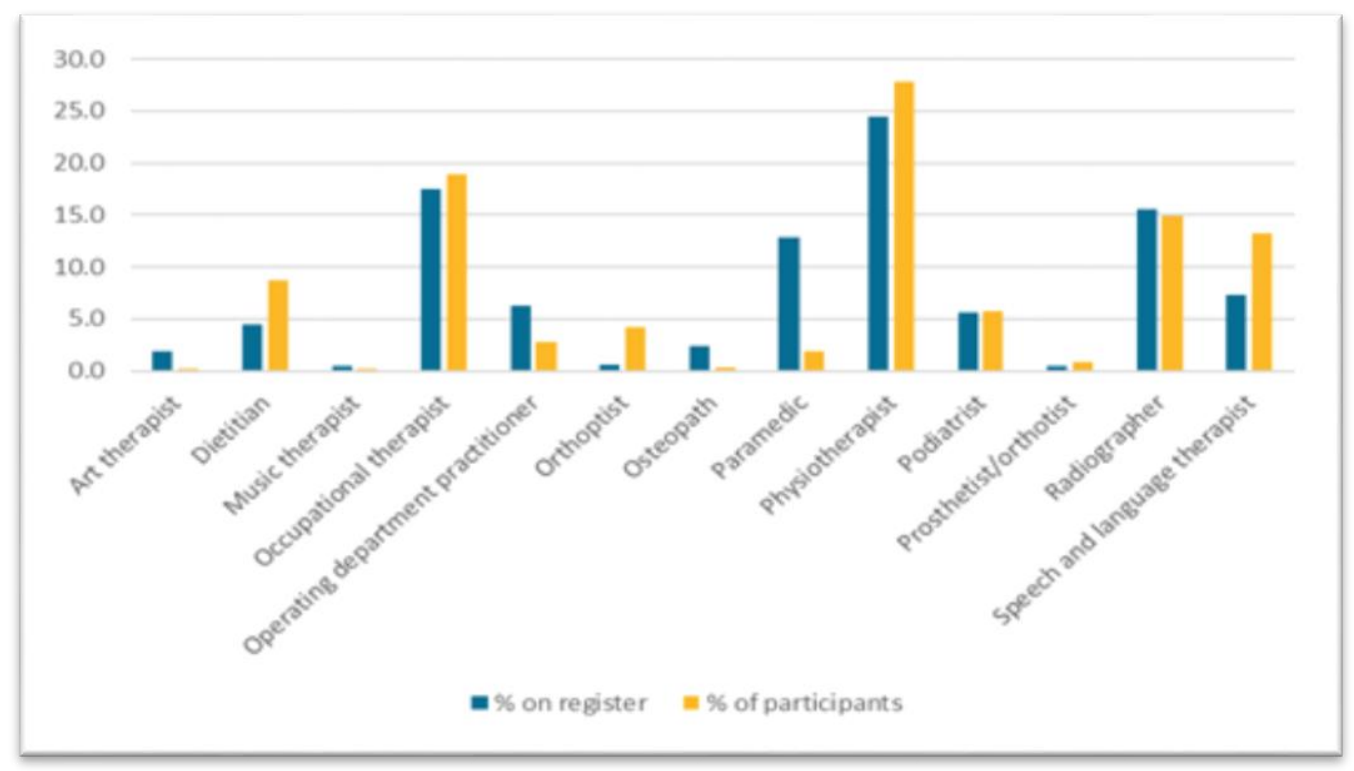

While HEE commissioned the project, it was open to anyone from across the UK, Europe, or globally, all of whom were encouraged to contribute. Participants from the four home nations (England, Northern Ireland, Scotland \& Wales) were encouraged to engage. Participants were asked to state which country they come from in the gateway questionnaire. Table 3 demonstrates the responses to question about location. Most participants were from the UK, in particular England. However, there were contributions from outside the UK, as far as Australia and New Zealand (although this demonstrates log-in occurrences, and not where people are usually based).

Table 3.

\section{Participant location}

\begin{tabular}{|ll|}
\hline Country & Percentage (\%) \\
\hline England & 84.1 \\
Northern Ireland & 2.0 \\
Scotland & 7.9 \\
Wales & 3.1 \\
\hline Australia & 0.9 \\
Canada & 0.4 \\
Egypt & 0.1 \\
\hline India & 0.2 \\
Latvia & 0.1 \\
New Zealand & 0.1 \\
\hline Portugal & 0.2 \\
Republic of Ireland & 0.8 \\
Not stated & 0.2 \\
\hline
\end{tabular}




\section{Qualitative data: Online workshop}

A total of six major themes were identified across the discussion (Table 4).

Table 4.

Themes and concepts from the online workshop

\begin{tabular}{|c|c|}
\hline Theme & Concept \\
\hline \multirow{7}{*}{ Diversity } & Location, supervision, timing \\
\hline & PIVOs/care homes/ primary care \\
\hline & Long arm supervision \\
\hline & Academic/teaching/research \\
\hline & Management/leadership \\
\hline & Public health \\
\hline & Professional bodies \\
\hline \multirow{4}{*}{ Coordination } & Placement facilitator roles \\
\hline & Leadership across the system \\
\hline & Regional/ National approach to allocations \\
\hline & Communication \\
\hline \multirow{3}{*}{ Joined up system } & National paperwork \\
\hline & Allocation models \\
\hline & More alignment/ standardisation \\
\hline \multirow{3}{*}{ Overall redesign } & $\begin{array}{l}\text { Distil out what needs to be completed where, i.e. what needs } \\
\text { patient contact, what can be achieved elsewhere }\end{array}$ \\
\hline & Use of simulation \\
\hline & Developing clinical decision-making skills \\
\hline \multirow{6}{*}{ Educator capacity } & Practice learning is everyone's business \\
\hline & Team approach \\
\hline & Supervision models. $2: 1 ; 3: 1 ; 4: 1$. CLiP model \\
\hline & Learning rather than teaching focus \\
\hline & Peer support \\
\hline & Long arm supervision \\
\hline \multirow{5}{*}{ Culture and attitude } & The language used "the student" \\
\hline & Inspire to hire \\
\hline & Part of the team \\
\hline & Creating pull in the system \\
\hline & Valuing students \\
\hline
\end{tabular}

\section{Diversity theme}

Within the diversity theme, many participants felt that utilising leadership or role emerging placements could promote different skill sets from a traditional placement, for example, being on a ward, care home or educational setting. Participants also linked this with working inter-professionally with other AHPs on placement, as it allows learners to build on more generic competencies such as communication and a better understanding of the patient pathway. Further ideas were presented around creating placements with other non-traditional providers and how these potentially added to the breadth of placements for learners. 
Diversity in placement locations was also highlighted. Ideas around placement planning also featured ideas like using shift patterns, using all 365 days of the year and re-thinking whether the 'set numbers of hours of placement' approach was still necessary across professions. Lastly, the individual's journey on placement was discussed. Understanding that learners may prefer a placement type, whether this relates to supporting their personal learning needs, a gap in their knowledge or profession-specific request, it is deemed essential to encourage student involvement in the placement allocation processes as they can plan their career path.

\section{Coordination}

The improved coordination theme addressed improving coordination and collaboration of all parties, placement providers, HEIs and learners when planning placements. This included managing expectations, capacity, and placement training for learners. Another popular idea was that all HEIs have a central regional or national database of capacity to distribute learners across localities. Ideas on supervision models favoured peer-assisted learning and inter-professional education, over the standard 1:1 model, which in turn could increase capacity across the system as well as offering diverse learning opportunities for learners.

\section{Joined up system}

Funding was identified as key to having these models in practice to provide concrete evidence for the effectiveness of these models and support wider acceptance and adoption. Placement providers also felt that funding could be used to incentivise practice educators for taking learners because the current system can mean they do not 'directly see' the placement tariff. Some agreed, but others suggested that recognition for educators could be just as important. Further support for learners, specifically minority ethnic learners, in managing stress and attrition was also highlighted.

\section{Coordinated approach}

The crowd discussed creating a central and national coordinated approach to placement allocation with standardised practices, involving multiple stakeholders, allocating placements, and facilitating consistent paperwork within professions and across professions. It was felt that this would remove administrative barriers to some placements, which some clinicians believe to exist. Ideas on how this would work in practice included taking a systems approach to map all placement capacity, which could be supported by professional bodies, HEIs and placement providers. This could lead to a fairer and more equitable allocation model, and centralising the system with access to all would support this.

\section{Overall redesign}

There was a call to completely re-think this structure, with statements around new routes into healthcare jobs via apprenticeships and the learner's final placement possibly being their first workplace, thus supporting the transition from learner to newly qualified practitioner (NQP). Some participants thought the term 'placement' could be reframed as 'practice-based learning' or a 'learning environment', so learners and educators can see it as a learning pathway. Several ideas suggested using and supporting a return to practice, with individuals to help recruitment issues and using their experience to enhance the capacity. The preparation of learners for placement was also identified as an issue for some clinicians. For students to be better prepared for placements, many ideas were based on HEIs' simulation-based learning before placement and handing over some 'clinical' learning and basic procedures, so learners are fully prepared.

\section{Educator capacity}

The educator capacity theme related to educators not having sufficient capacity (time), especially when asked to have a student. Solutions included having ring-fenced time to teach learners to give the student the best experience, but with a smaller clinical caseload, to protect 'learning time'. Having a primary placement facilitator within the organisation was listed as a mechanism for ensuring a coordinated teaching approach and allowing clinicians' development time. Alongside the education component, the placement facilitator could also have administrative tasks like having IT access and Smart cards for all learners before placements, as this is a big issue currently. 


\section{Placement culture and attitudes}

The ideas analysed for this theme suggested that there needs to be a positive mindset about having a student with contributors saying that they are an 'integral part of the team' and 'should be accepted by all and supervised by all'. The crowd proposed that this can be undertaken via a whole team approach to allow the student to be valued. Another area noted was allowing any department to take learners, with participants highlighting that no location is too specialist to take a student and that every grade from support workers to AHP directors should be encouraged to take learners, thus offering valuable experiences for learners of the whole patient pathway.

\section{Limitations of the study}

Due to the pandemic and various lockdown restrictions, the only way to conduct this research was through virtual communication. While online methods can effectively reach portions of the population, obtaining representative participation requires integrating other forms of participation, including face-toface deliberative. Nevertheless, the data presented in the results section demonstrates engagement from a good spread of individuals across a vast geography.

\section{Impact of this study}

Via analysis of the crowdsourced data, a national call to action was developed:

- $\quad$ Supporting AHP learner placements anywhere

- Look to other AHP professions for clinical placement models and inspiration

- Learner-centred and learner-focused placements

- Harnessing system-wide working

This, together with the insights generated through the crowdsource, resulted in HEE announcing in August 2020 that $£ 6.8$ million would be available for significant AHP placements growth and development, representing 50\% more monies than originally pledged (HEE, 2020) and £1million being specifically allocated to evaluate technology-enhanced placements.

In response to the crowdsourcing themes, particularly the barriers, a pre-registration AHP Student Practice Learning Programme was developed to increase practice learning capacity and maintain/improve quality. This programme incorporates the $£ 6.8$ million investment into placement expansion. As demonstrated in Figure 6, the programme aspires to address this via five objectives.

\section{Conclusion}

Access to high-quality placements is critical to meeting the NHS Long Term Plan ambition of increasing the numbers within the Allied Health Professions workforce. The COVID-19 pandemic has compounded an ongoing challenge of accessing and growing placement capacity. Equally, it has offered an opportunity to capture the creative activity due to this low frequency, high impact global event. When deliberative face-to-face activity was impossible, crowdsourcing offered a technological enabler to support stakeholder engagement in discussing and sharing good practices across England, the four nations, and beyond. The findings of this work have directly resulted in targeted funding to 2020/2021 HEE funded Clinical Placement Expansion Programme activities and the development of objectives for the wider preregistration AHP Student Practice Learning programme.

\section{Data sharing statement}

Due to the consent process for participants, this study has not been reviewed by an ethics committee; therefore, the qualitative research data (supporting direct quotes) are not available for sharing. However, ethical principles have been upheld. Moreover, Dr Julie Woodley, one of the co-authors, holds a PhD in healthcare ethics and has advised on this aspect of the research. 
Figure 6.

Pre-Registration AHP student Practice Learning Programme Objectives

1. Increasing placement capacity by a minimum of 1500 places as required by the $N H S$ Long Term Plan through accessing a wide range of placement settings across the health and social care system and settings expanded to include private community care, primary care, voluntary and third sectors to support confidence and the required workforce growth

2. Clarifying, communicating, and supporting changes (if required) to the professional regulatory body and national policy to support the required expansion

3. Evaluating the impact of the investment funding for CPEF, including the $£ 1,000,000$ to evaluate technology-enhanced placements, including return on investment

4. Providing a suite of resources to support expansion via innovation and spread of best practice. This includes a learning webinar series and quick guides

5. Offer a sustainable approach to sharing best practice and innovation via a repository

\section{Conflict of Interest statement}

Health Education England commissioned Clever Together in June 2020 to run the online workshop and generate insight on the impact of COVID-19 on placement capacity and how AHP placement provision could be expanded and improved. Fiona Martin, a co-author of this article, is the operational manager at the company. Janice St. John-Matthews, the lead author, uses the Clever Together platform in her doctorate work which investigates stakeholder involvement (patients, public, students) in healthcare curriculum design processes.

\section{Acknowledgements}

The team wishes to extend a thank you to those who engaged with and contributed to the crowdsource. Without these individual contributions there would be no report, follow-up actions and increased funding to support the 2020/2021 placement expansion activities across England.

\section{Sources of funding}

This work was commissioned by Health Education England (HEE).

\section{ORCID}

Janice St. John-Matthews https://orcid.org/0000-0003-0145-9369

Fiona Martin https://orcid.org/0000-0002-9345-0814

Julie Woodley https://orcid.org/0000-0002-2142-0843

\section{References}

Aitamurto, T. (2012). Crowdsourcing for democracy: A new era in policymaking. Parliament of Finland: Publication of the Committee of the Future. http://www.cnid.cl/wpcontent/uploads/2015/05/Crowdsourcing-for-Democracy.-Finlandia-2012.pdf

Akkermans, J., Richardson, J., \& Kraimer, M. L. (2020). The COVID-19 crisis as a career shock: Implications for careers and vocational behaviour. Journal of Vocational Behaviour, 119, 103434. https://doi.org/10.1016/j.jvb.2020.103434

Brabham, D. C. (2008). Crowdsourcing as a model for problem solving: An introduction and cases. Convergence, 14(1), 75-90. https://doi.org/10.1177/1354856507084420 
Brabham, D. C. (2013). Crowdsourcing: The MIT Press essential knowledge series. The MIT Press. https://mitpress.mit.edu/books/crowdsourcing

Braun, V., \& Clarke, V. (2006). Using thematic analysis in psychology: Qualitative research in psychology. Qualitative Research in Psychology, 3(2), 77-101. https://doi.org/10.1191/1478088706qp063oa

Braun, V., \& Clarke, V. (2019). Reflecting on reflexive thematic analysis. Qualitative Research in Sport, Exercise and Health, 11(4), 589-597. https://doi.org/10.1080/2159676X.2019.1628806

Clever Together. (2020). Clever Together Lab Ltd. https://clevertogether.com

Department of Health \& Social Care. [DHSC]. (2020). Universities can bid for more healthcare course places. GOV.UK. https://www.gov.uk/government/news/universities-can-bid-for-morehealthcare-course-places

Efron, S. E., \& Ravid, R. (2020). Action Research in education: A practical guide (2nd edition). The Guildford Press.

Eklund, L., Stamm, I., \& Liebermann, W. K. (2019). The crowd in crowdsourcing: Crowdsourcing as a pragmatic research method. First Monday, 4(10). https://doi.org/10.5210/fm.v24i10.9206

Estellés-Arolas, E., \& González-Ladrón-de-Guevara, F. (2012). Towards an integrated crowdsourcing definition. Journal of Information Science, 38(2). https://doi.org/10.1177/0165551512437638

Estellés-Arolas, E., Navarro-Giner, R., \& González-Ladrón-de-Guevara, F. (2015). Crowdsourcing Fundamentals: Definition and Typology. In F. J. Garrigos-Simon, I. Gil-Pechuán, \& S. EstellesMiguel (Eds.), Advances in Crowdsourcing (pp. 33-48). Springer International. https://doi.org/10.1007/978-3-319-18341-1_3

Fenton, P. (2005). Student perceptions of a quality clinical experience: Findings from the literature and their application to radiation therapy. Radiographer, 52(1), 30-33. https://doi.org/10.1002/j.2051-3909.2005.tb00028.x

Flostrand, A. (2017). Finding the future: Crowdsourcing versus the Delphi technique. Business Horizons, 60(2), 229-236. https://doi.org/10.1016/j.bushor.2016.11.007

Health Education England [HEE]. (2017). Allied Health Professions: Maximising their potential to transform services. Health Education England. https://www.hee.nhs.uk/our-work/allied-healthprofessions

Health Education England [HEE]. (2020). Placement expansion and innovation. Health Education England. https://www.hee.nhs.uk/our-work/allied-health-professions/helping-ensure-essentialsupply-ahps/placement-expansion-innovation

Howe, J. (2006, June 1). The rise of crowdsourcing. Wired Magazine, 14, 1-4. http://www.wired.com/wired/archive/14.06/crowds.html

Lorenz, J., Rauhut, H., Schweitzer, F., \& Helbing, D. (2011). How social influence can undermine the wisdom of the crowd effect. Proceedings of the National Academy of Sciences of the United States of America, 108(22), 9020-9025. https://doi.org/10.1073/pnas.1008636108

NHS England [NHSE]. (2020). We are the NHS: People Plan for 2020/2021-Action for us all. NHS People Plan. https://www.england.nhs.uk/ournhspeople/

NHS England \& Improvement [NHSE\&I]. (2020). About Allied Health Professions (AHPs). https://www.england.nhs.uk/ahp/

NHS Improvement [NHSI]. (2018). Clinical leadership-A framework for action |NHS Improvement. https://improvement.nhs.uk/resources/clinical-leadership-framework-action/

Skelton, E., Drey, N., Rutherford, M., Ayers, S., \& Malamateniou, C. (2020). Electronic consenting for conducting research remotely: A review of current practice and key recommendations for using e-consenting. International Journal of Medical Informatics, 143, 104271. https://doi.org/10.1016/j.ijmedinf.2020.104271

St. John-Matthews, J., Newton, P. M., Grant, A. J., \& Robinson, L. (2019). Crowdsourcing in health professions education: What radiography educators can learn from other disciplines. Radiography, 25(2), 164-169. https://doi.org/10.1016/j.radi.2018.11.006

Taeihagh, A. (2017). Crowdsourcing: A new tool for policymaking? Policy Sciences, 50, 629-647. https://doi.org/10.1007/s11077-017-9303-3

World Health Organisation. [WHO]. (2020). WHO Coronavirus Disease (COVID-19) Dashboard. https://covid19. who.int

Wynne, B. (2007). Public participation in science and technology: Performing and obscuring a politicalconceptual category mistake. East Asian Science, Technology and Society: An International Journal, 1(1), 99. DOI: 10.1007/s12280-007-9004-7 